\title{
Expression and clinical significance of RCDG1 in renal cell carcinoma: A novel renal cancer-associated gene
}

\author{
ZUHU YU ${ }^{1-3}$, LIANGCHAO NI ${ }^{1}$, DUQUN CHEN ${ }^{1,3}$, ZHENGMING SU $^{1,4}$, WENSHUI YU $^{1,4}$, \\ QIANG ZHANG ${ }^{1}$, YADONG WANG ${ }^{1}$, CAILING LI $^{2}$, YAOTING GUI ${ }^{1,2}$ and YONGQING LAI ${ }^{1,2}$
}

\begin{abstract}
${ }^{1}$ Department of Urology, Peking University Shenzhen Hospital, Shenzhen, Guangdong 518036; ${ }^{2}$ The Key Laboratory of Stem Cell Biology, Guangdong and Shenzhen Key Laboratory of Male Reproductive Medicine and Genetics, Institute of Urology, Peking University Shenzhen Hospital, Shenzhen PKU-HKUST Medical Center, Shenzhen, Guangdong 518036;

${ }^{3}$ Anhui Medical University, Anhui, Hefei 230032; ${ }^{4}$ Shantou University Medical College, Shantou, Guangdong 515041, P.R. China
\end{abstract}

Received September 6, 2013; Accepted November 14, 2013

DOI: $10.3892 / \mathrm{mmr} .2014 .2388$

\begin{abstract}
Recently identified molecular tumor markers have numerous potential applications in the diagnosis, therapy and prognostic prediction of renal cell carcinoma (RCC). Through bioinformatics-based screening approaches together with validation of western blot and immunohistochemical data, the present study identified a novel renal cancer-associated gene, preliminarily named Renal Cancer Differentiation Gene 1 (RCDG1), originally known as chromosome 4 open reading frame 46 (C4orf46). RCDG1 expression was evaluated by western blot analysis of RCC and adjacent normal tissues, renal cancer cell lines and normal kidney HEK293T cells. Additionally, RCDG1 expression was assessed in 124 RCC paraffin sections, including 92 paired adjacent normal tissues, by immunohistochemistry. The results showed that RCDG1 was significantly downregulated in RCC tissues as compared with normal adjacent tissues $(\mathrm{P}<0.001)$, and the expression of RCDG1 in clear cell (cc) RCC tissues was significantly lower as compared with that of non-ccRCC tissues $(\mathrm{P}=0.005)$. Furthermore, statistical analysis revealed RCDG1 expression was negatively correlated with the Fuhrman grade in ccRCC $(\mathrm{P}=0.008)$. A reduction in RCDG1 expression may be associated with the oncogenesis of RCC and the differentiation of
\end{abstract}

Correspondence to: Professor Yongqing Lai, Department of Urology, Peking University Shenzhen Hospital, Institute of Urology of Shenzhen PKU-HKUST Medical Center, 1120 Lianhua Road, Shenzhen, Guangdong 518036, P.R. China

E-mail: yqlord@163.com

Professor Yaoting Gui, The Key Laboratory of Stem Cell Biology, Guangdong and Shenzhen Key Laboratory of Male Reproductive Medicine and Genetics, Institute of Urology, Peking University Shenzhen Hospital, Shenzhen PKU-HKUST Medical Center, 1120 Lianhua Road, Shenzhen, Guangdong 518036, P.R. China E-mail: guiyaoting2007@yahoo.com.cn

Key words: RCDG1, renal cell carcinoma, western blot, immunohistochemistry
ccRCC. Further studies may provide more information about the function of RCDG1 gene in RCC.

\section{Introduction}

Renal cell carcinoma (RCC) is the most common malignant tumor of the adult kidney. It accounts for $3 \%$ of adult malignancies and $\sim 90 \%$ of all renal neoplasms (1). RCC is a highly vascularized tumor that originates in the renal cortex, with a steadily increasing annual incidence rate of $2.6 \%$ (2). Approximately $30 \%$ of patients have metastasis when initially diagnosed with RCC and up to $30 \%$ of patients with clinically localized disease develop cancer recurrence following surgery $(3,4)$. Although novel therapeutic strategies have improved the treatment of RCC, the prognoses of patients with RCC remain unfavorable, particularly for those with advanced tumors $(5,6)$.

According to the World Health Organization International Histological Classification of Kidney Tumors, RCC was subdivided into clear cell renal cell carcinoma (ccRCC), papillary RCC, chromophobe RCC, collecting duct carcinoma and unclassified renal carcinoma, based on histological and genetic differences (2,7). Approximately $80 \%$ of RCCs are classified as clear cell RCC (ccRCC), which is the most aggressive form of RCC with the highest rate of metastasis and poorest survival among common renal malignancies $(8,9)$. Although great progress has been made, the underlying molecular mechanisms of tumorigenesis and progression of ccRCC are still not entirely clear (10-13).

Molecular markers are able to provide information on the occurrence and aggressiveness of RCC, allowing for the development of more targeted and effective strategies for early detection and treatment of RCC $(14,15)$. Current markers are inadequate to substantially alter existing diagnostic, therapeutic and prognostic strategies of RCC. Therefore, it is essential to identify novel renal cancer-associated genes. By means of bioinformatic approaches, a novel renal cancer-associated gene newly named Renal Cancer Differentiation Gene 1 (RCDG1) in the present study [previously known as chromosome 4 open reading frame 46 (C4orf46); gene ID: 201725], was identified. The expression of RCDG1 in RCC, ccRCC and 
normal kidney tissues was examined using western blot and immunohistochemical analyses. Statistical analysis was then performed to identify any correlation between RCDG1 levels and clinicopathological characteristics of the patients.

\section{Materials and methods}

Patients and tissue specimens. The tissue specimens used in the present study, including the paraffin sections of 124 RCC and 92 paired adjacent normal tissues (located $2.0 \mathrm{~cm}$ outside of visible RCC lesions) and fresh RCC and adjacent normal tissues, were collected from patients who underwent radical nephrectomy at the Department of Urology, Peking University Shenzhen Hospital (Shenzhen, China). Clinical and pathological characteristics of these 124 RCC patients are listed in Table I. The fresh RCC tissues and adjacent normal tissues, including eight ccRCCs and four papillary carcinomas, were stored at $-80^{\circ} \mathrm{C}$ following dissection. All of these tissue specimens were clinically and pathologically confirmed to be RCC-positive or normal tissues, by experienced pathologists of the Pathology Department, Peking University Shenzhen Hospital (Shenzhen, China). All tissue samples were classified according to the American Joint Committee for Cancer (AJCC) and Fuhrman nuclear grading (16). The study was approved by the Ethics Committee of Peking University Shenzhen Hospital (Shenzhen, China). Written informed consent was obtained from all patients and the study was reviewed and approved by the Hospital Ethics Committees.

Perl programming to screen candidate genes in silico. To screen for novel renal cancer-associated genes in silico, the following steps were performed as previously described (17). A secondary classification database for expressed sequence tag (EST) libraries was generated based on the Cancer Genome Anatomy Project (CGAP) information of EST libraries (18). The CGAP EST libraries were classified into two classes: Libraries from nonfetal, nongerminal and nonplacental normal tissues (NT), and libraries from renal cancer. Furthermore, Unigene clusters with $<20$ ESTs from NT libraries and $>2$ ESTs from renal cancer libraries were screened. The frequency of the best serial analysis of gene expression (SAGE) tag in NT for each candidate gene was counted based on CGAP SAGE data and Unigene clusters with $<20$ SAGE tags from NT were retained for further analysis. Finally, the candidate genes were analyzed manually using an Affymetrix HG-U133AB microarray data of normal tissues downloaded from the University of California at Los Angeles public core.

Cell lines and culture condition. Human renal cancer cell lines, 786-O, ACHN, 769-P, Caki-2 and human kidney HEK293T cells were obtained from the Key Laboratory of Male Reproductive Medicine and Genetics (Guangdong, China) were used for western blot analysis of RCDG1 expression in this study. These cells were cultured in Dulbecco's Modified Eagle's Medium (Thermo Fisher Scientific, Waltham, MA, USA) supplemented with $10 \%$ fetal bovine serum, at $37^{\circ} \mathrm{C}$ in a humidified incubator containing $5 \% \mathrm{CO}_{2}$.

Quantitative polymerase chaine reaction ( $q P C R)$ evaluation for the mRNA of RCDG1. Total RNA from 12 paired renal caner tissues and adjacent normal tissues was extracted using TRIzol solution (Invitrogen, Carlsbad, CA, USA), treated with Revert Aid First Strand cDNA Synthesis kit (MBI Fermentas Inc., Burlington, ON, Canada) to obtain the cDNA templates according to the manufacturer's instructions. The cDNA was then subjected to qPCR for evaluation of the relative mRNA levels of RCDG1 and GAPDH (as an internal control) with the corresponding primer pairs: Sense: 5'-GGAGACGCAGCCTTTTCATTA-3' and antisense: 5'-GTCCCGCCACGTTTTAAGGA-3' for RCDG1; and sense: 5'-CACCAGGGCTGCTTTTAACTC-3' and antisense: 5'-GAAGATGGTGATGGGATTTC-3' for GAPDH. The reaction mixture was set up in a total volume of $20 \mu 1$, consisting of $1 \mu \mathrm{l}$ cDNA template synthesized previously, $10 \mu \mathrm{l} \mathrm{SYBR}$ Green master mix (Invitrogen), $1 \mu l$ of each primer (sense and antisense primer) and RNase-free water. Cycling parameters were set as follows: $95^{\circ} \mathrm{C}$ for $2 \mathrm{~min}$, followed by 40 cycles of $95^{\circ} \mathrm{C}$ for $15 \mathrm{sec}, 55^{\circ} \mathrm{C}$ for $30 \mathrm{sec}$ and $72^{\circ} \mathrm{C}$ for $40 \mathrm{sec}$. The expression levels were calculated using the $\Delta \Delta \mathrm{Ct}$ method.

Western blot analysis of RCDG1 expression. Collected cells of cell lines used in this study and the frozen fresh samples were homogenised on ice in three volumes of lysis buffer $[150 \mathrm{mM} \mathrm{NaCl}, 20 \mathrm{mM}$ Tris- $\mathrm{HCl}$ (pH 7.4), 0.1\% SDS, $1 \%$ sodium deoxycholate, $1 \%$ Triton X-100, $5 \mathrm{mgml}$ aprotinin, and $1 \mathrm{mgml}$ leupeptin; Thermo Fisher Scientific, Waltham, MA, USA]. Protein concentration was quantified using the Pierce Bicinchoninic Acid Protein Assay kit (Thermo Fisher Scientific) and protein samples (100 $\mu \mathrm{g})$ were separated by $10 \%$ SDS-PAGE and transferred onto nitrocellulose membranes. After blocking the membranes with $10 \%$ fat-free milk at room temperature for $2 \mathrm{~h}$, the membranes were incubated in primary antibodies overnight at $4^{\circ} \mathrm{C}$. RCDG1 (previously known as C4orf46) and $\beta$-actin proteins were identified with the primary antibodies rabbit polyclonal anti-C4orf46 (1:1,000, Sigma, St. Louis, MO, USA) to detect RCDG1 and sc-47778 (1:400, Santa Cruz Biotechnology, Santa Cruz, CA, USA), respectively. The membranes were washed three times with Tris-buffered saline containing Tween-20 and incubated for $2 \mathrm{~h}$ with secondary antibody goat anti-rabbit immunoglobulin (Ig)G-horse radish peroxidase (HRP) (sc-2004) or goat anti-mouse IgG-HRP (sc-2005). The protein bands were detected with the Immun-Star ${ }^{\mathrm{TM}}$ HRP Chemiluminescence kit peroxide buffer and luminolenhancer (Bio-Rad Laboratories, Hercules, CA, USA). Each assay was repeated at least three times.

Immunohistochemistry (IHC). IHC analysis of RCDG1 was performed according to standard procedures. Briefly, paraffin-embedded samples were cut into $5 \mu \mathrm{m}$ sections, dewaxed in xylene and rehydrated in a descending ethanol series, followed by incubation in 3\% hydrogen peroxide solution for $20 \mathrm{~min}$. Antigen retrieval was performed by boiling the sections in a microwave oven for $2 \times 15 \mathrm{~min}$ in $0.01 \mathrm{M}$ citrate buffer ( $\mathrm{pH}$ 6.0). The sections were washed with phosphate-buffered saline (PBS) three times for $5 \mathrm{~min}$, and the sections were then treated with $10 \%$ bovine serum albumin for $30 \mathrm{~min}$ at $37^{\circ} \mathrm{C}$ to block non-specific protein binding. For the immunostaining of RCDG1, the specimens were treated with rabbit polyclonal antibody anti-C4orf46 (1:800, Sigma, USA) 
Table I. Clinicopathologic characteristics of 124 patients with RCC.

\begin{tabular}{lc}
\hline Characteristics & Cases, $\mathrm{n}(\%)$ \\
\hline Age (years) & \\
$<60$ & $62(50.0)$ \\
$\geq 60$ & $62(50.0)$ \\
Gender & \\
Male & $88(71.0)$ \\
Female & $36(29.0)$ \\
Histological type & \\
Clear cell RCC & $60(48.4)$ \\
Papillary RCC & $34(27.4)$ \\
Chromophobe RCC & $28(22.6)$ \\
Collecting duct carcinoma & $2(1.6)$ \\
Fuhrman grade & \\
G1-2 & $54(43.5)$ \\
G3 & $43(34.7)$ \\
G4 & $27(21.8)$ \\
AJCC clinical stage & \\
T1 & $78(62.9)$ \\
T2 & $33(26.6)$ \\
T3-4 & $13(10.5)$ \\
\hline
\end{tabular}

RCC, renal cell carcinoma; AJCC, American Joint Committee for Cancer.

to detect RCDG1 overnight at $4^{\circ} \mathrm{C}$. The samples were then rinsed with PBS three times and treated with the anti-rabbit IHC kit (Maixin Bio; Fujian, China) at $37^{\circ} \mathrm{C}$ for $30 \mathrm{~min}$. Subsequently, the slides were stained with 3'3-diaminobenzidine tetrahydrochloride (Maixin Bio, Fujian, China) for $3 \mathrm{~min}$, counterstained with hematoxylin (Maixin Bio), dehydrated, and mounted. Negative controls were prepared with omission of the primary antibodies.

Evaluation of the staining was carried out by two independent pathologists who were blinded to the clinicopathologic variables with a two-score system of immunointensity (II) and immunopositivity (IP) $(19,20)$. II was graded as follows: 0 , no staining; 1 , weakly stained; 2 , moderately stained; 3 , highly stained. The percentage of cells with IP was graded as follows: $0, \leq 1 ; 1,2-25 ; 2,26-50 ; 3,51-75$ and $4, \geq 75 \%$. All of the paraffin-embedded sections were given final scores based on the multiplications of the II and IP score. A final score of 0-12 was graded as negative (I, 0-1), weak (II, 2-4), moderate (III, 5-8), and strong (IV, 9-12). In case of any discrepancy, the specimens were evaluated by the two observers together until a final score was agreed.

Statistical analysis. Statistical analyses were performed using SPSS 17.0 (IBM, Armonc, NY, USA). The $\chi^{2}$ test was used to make comparisons between RCC tissues and adjacent normal tissues, as well as the comparison between ccRCC and non-ccRCC tissues. Relationships between the expression of RCDG1 and clinicopathologic variables were

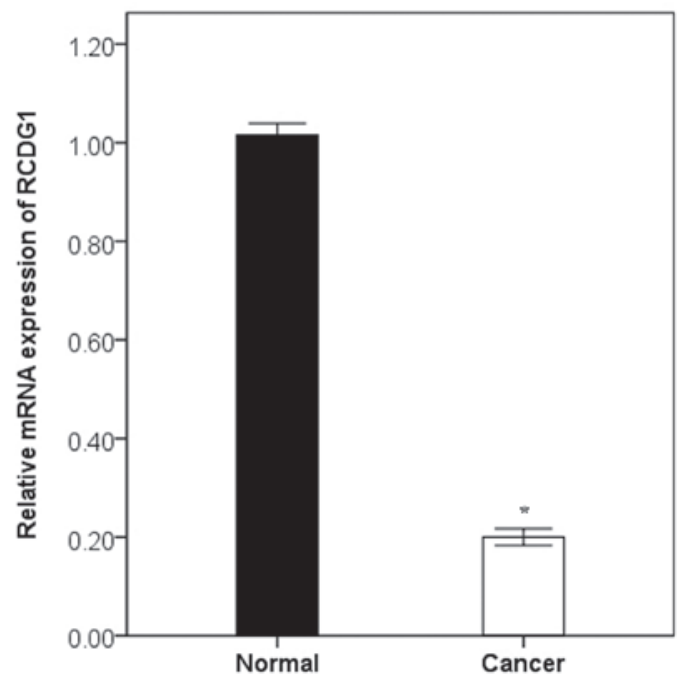

Figure 1. Quantitative polymerase chain reaction evaluation for mRNA expression in 12 paired renal cell carcinoma tissues and adjacent normal tissues $($ ( $\mathrm{P}<0.001)$.

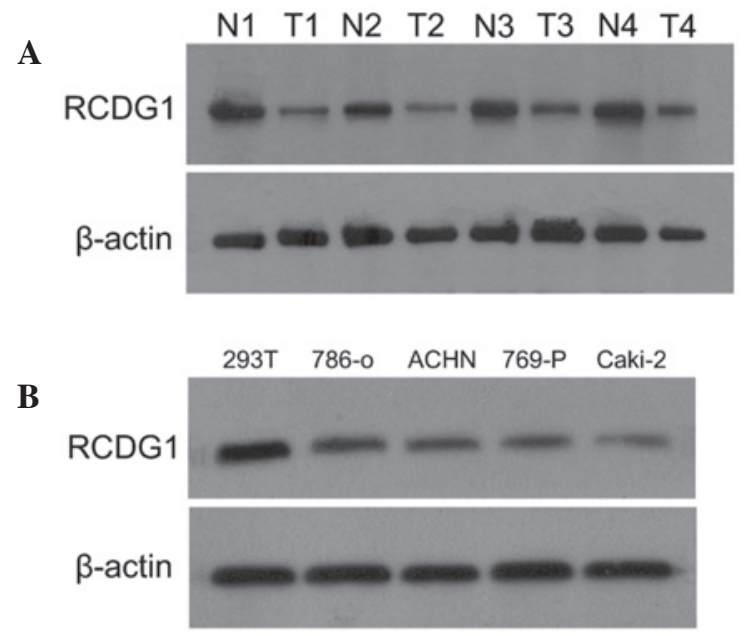

Figure 2. Protein expression of RCDG1 in renal tissues and cell lines, analyzed by western blot. (A) Four representative pairs of renal cell carcinoma and adjacent normal tissues are presented. (B) RCDG1 expression in HEK293T and renal cancer cell lines 786-O, ACHN, 769-P, Caki-2. All results are representatives of three independent experiments. $\mathrm{N}$, adjacent normal tissue; $\mathrm{T}$, tumor tissue.

calculated using the Kruskal-Wallis and Mann-Whitney rank sum tests. $\mathrm{P}<0.05$ was considered to indicate a statistically significant difference.

\section{Results}

Results of in silico screening and qPCR evaluation. A total of 32 candidate clusters were first screened out by Perl programming based on EST data. Following secondary analysis using SAGE and microarray data, the data was narrowed to nine clusters, with reconfirmed high expression in normal tissues. The nine clusters were ranked according to the number of EST from renal cancer and qPCR was performed to evaluate the renal cancer specificity. In the first five genes evaluated, C4orf46 (chromosome 4 open reading frame 46) was highly 
Table II. Expression of RDCG1 in renal cell carcinoma and normal tissues ( $\chi^{2}$ test).

\begin{tabular}{|c|c|c|c|c|c|c|}
\hline \multirow[b]{2}{*}{ Histology } & \multirow[b]{2}{*}{ Positive cases, n (\%) } & \multicolumn{4}{|c|}{ RDCG1 expression, $\mathrm{n}(\%)$} & \multirow[b]{2}{*}{ P-value } \\
\hline & & I & II & III & IV & \\
\hline Normal (n=92) & $90(97.8)$ & $2(2.2)$ & $1(1.1)$ & $4(4.3)$ & $85(92.4)$ & $<0.001$ \\
\hline $\operatorname{RCC}(n=124)$ & $66(53.2)$ & $58(46.8)$ & $45(36.3)$ & $21(16.9)$ & 0 & \\
\hline $\operatorname{ccRCC}(\mathrm{n}=60)$ & $23(38.3)$ & $37(61.7)$ & $15(25.0)$ & $8(13.3)$ & 0 & 0.005 \\
\hline Non-ccRCC $(n=64)$ & $43(67.2)$ & $21(32.8)$ & $30(46.9)$ & $13(20.3)$ & 0 & \\
\hline
\end{tabular}

RCC, renal cell carcinoma; cc, clear cell.

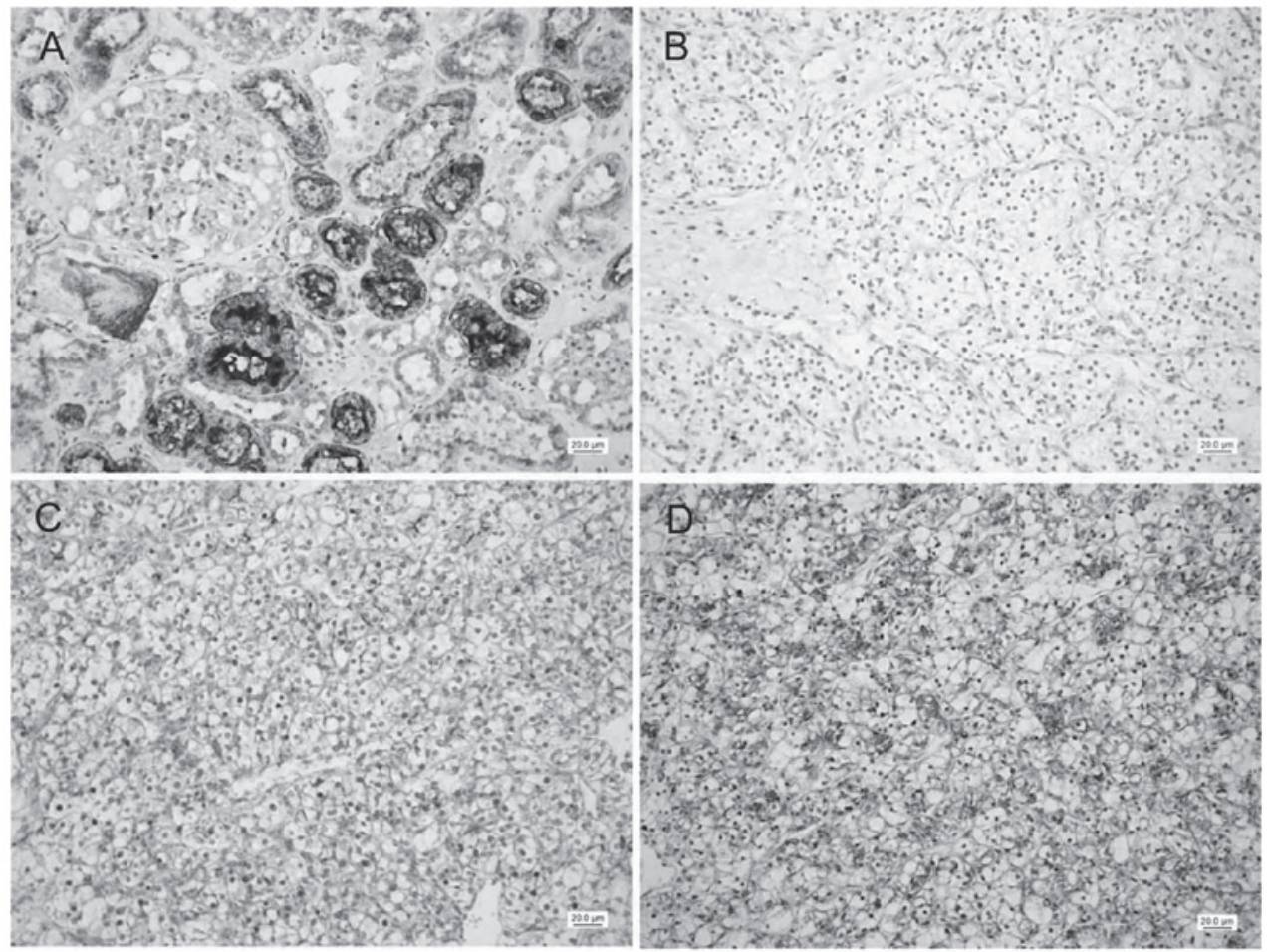

Figure 3. Immunohistochemical staining of RDCG1 in renal cell carcinoma tissues and normal tissues (magnification, x200). (A) Normal kidney tissues showed strong staining. (B) Negative staining of renal cell carcinoma tissues. (C) Weak staining of renal cell carcinoma tissues. (D) Moderate staining of renal cell carcinoma tissues.

specific for renal cancer and it was therefore temporarily termed RCDG1 (Fig. 1).

Western blot analysis of RCDG1 protein levels in RCC tissues and cell lines. Western blotting was performed to determine the expression levels of RCDG1 in RCC and adjacent normal tissues, as well as in RCC cell lines and HEK-293T cells. As shown in Fig. 2A, RCDG1 protein was expressed in both RCC tissues and adjacent normal tissues. The expression levels of RCDG1 in RCC tumor tissues (T) were significantly lower as compared with those of adjacent normal tissues $(\mathrm{N})$. This difference in expression was consistently observed in RCC lines (786-O, ACHN, 769-P and Caki-2) as compared with normal HEK293T cells (Fig. 2B).

IHC analysis of the expression of RCDG1 in RCC tissues and adjacent normal tissues. In total, 124 RCC tissues and 92 cases of adjacent normal tissues were used for detection of RCDG1 protein expression by IHC. In normal renal tissues, 90 (97.8\%) cases showed positive immunostaining (score $\geq 2$ ) with a total average score of $9.6 \pm 0.3$ and $85(92.4 \%)$ cases showed strong staining (score $\geq 9$ ) of RCDG1. As shown in Fig. 3, epithelial cells in renal tubules, including the proximal tubules and distal convoluted tubules, showed strong cytoplasmic staining of RCDG1. By contrast, 66 (53.2\%) cases showed positive staining and none of the tissue samples were found to be strongly stained. Statistic analysis demonstrated RCDG1 protein expression levels in RCC tissues were significantly lower than those in normal tissues $\left(\mathrm{P}<0.001\right.$ by $\chi^{2}$ test; Table II).

Twenty-three (38.3\%) cases of ccRCC tissues showed positive staining of RCDG1 (Table II). Respectively, 21 cases of papillary RCC (61.8\%) showed positive staining and 21 cases of chromophobe RCC tissues (75.0\%) showed positive immunostaining (Table III). Of the two cases of collecting duct 
Table III. Correlation between RDCG1 expression and clinicopathologic characteristics of patients with non-clear cell renal cell carcinoma.

\begin{tabular}{|c|c|c|c|c|}
\hline \multirow[b]{2}{*}{ Characteristics } & \multicolumn{3}{|c|}{ RDCG1 expression, n (\%) } & \multirow[b]{2}{*}{ P-value } \\
\hline & I & II & III & \\
\hline \multicolumn{5}{|l|}{ Age (years) } \\
\hline$<60(\mathrm{n}=30)$ & $12(40.0)$ & $14(46.7)$ & $4(13.3)$ & 0.145 \\
\hline$\geq 60(n=34)$ & $9(26.5)$ & $16(47.0)$ & $9(26.5)$ & \\
\hline \multicolumn{5}{|l|}{ Gender } \\
\hline Male $(n=49)$ & $18(36.7)$ & $22(44.9)$ & $9(18.4)$ & 0.233 \\
\hline Female $(n=15)$ & $3(20.0)$ & $8(53.3)$ & $4(26.7)$ & \\
\hline \multicolumn{5}{|l|}{ Histological type } \\
\hline Papillary RCC (n=34) & $13(38.2)$ & $13(38.2)$ & $8(23.6)$ & 0.938 \\
\hline Chromophobe RCC (n=28) & $7(25.0)$ & $17(60.7)$ & $4(14.3)$ & \\
\hline Collecting duct carcinoma $(n=2)$ & $1(50.0)$ & 0 & $1(50.0)$ & \\
\hline \multicolumn{5}{|l|}{ Fuhrman grade } \\
\hline $\mathrm{G} 1-2(\mathrm{n}=29)$ & $10(34.5)$ & $15(51.7)$ & $4(13.8)$ & 0.310 \\
\hline G3 $(n=24)$ & $9(37.5)$ & $10(41.7)$ & $5(20.8)$ & \\
\hline G4 $(n=11)$ & $2(18.2)$ & $5(45.4)$ & $4(36.4)$ & \\
\hline \multicolumn{5}{|l|}{ Tumor stage } \\
\hline $\mathrm{T} 1(\mathrm{n}=35)$ & 15 (42.9) & $14(40.0)$ & $6(17.1)$ & 0.239 \\
\hline $\mathrm{T} 2(\mathrm{n}=21)$ & $4(19.0)$ & $13(62.0)$ & $4(19.0)$ & \\
\hline T3-T4 $(n=8)$ & $2(25.0)$ & $3(37.5)$ & $3(37.5)$ & \\
\hline
\end{tabular}

RCC, renal cell carcinoma.

Table IV. Correlation between RDCG1 expression and clinicopathologic characteristics of patients with clear cell renal cell carcinoma.

\begin{tabular}{|c|c|c|c|c|}
\hline \multirow[b]{2}{*}{ Characteristics } & \multicolumn{3}{|c|}{ RDCG1 expression, $\mathrm{n}(\%)$} & \multirow[b]{2}{*}{ P-value } \\
\hline & I & II & III & \\
\hline \multicolumn{5}{|l|}{ Age (years) } \\
\hline$<60(\mathrm{n}=32)$ & $18(56.3)$ & $9(28.1)$ & $5(15.6)$ & 0.359 \\
\hline$\geq 60(n=28)$ & $19(67.9)$ & $6(21.4)$ & $3(10.7)$ & \\
\hline \multicolumn{5}{|l|}{ Gender } \\
\hline Male $(n=39)$ & $22(56.4)$ & $11(28.2)$ & $6(15.4)$ & 0.263 \\
\hline Female $(\mathrm{n}=21)$ & $15(71.4)$ & $4(19.1)$ & $2(9.5)$ & \\
\hline \multicolumn{5}{|l|}{ Fuhrman grade } \\
\hline G1-2 $(n=25)$ & $10(40.0)$ & $11(44.0)$ & $4(16.0)$ & 0.008 \\
\hline G3 $(n=19)$ & $12(63.2)$ & $4(21.0)$ & $3(15.8)$ & \\
\hline G4 $(n=16)$ & $15(93.7)$ & 0 & $1(6.3)$ & \\
\hline \multicolumn{5}{|l|}{ Tumor stage } \\
\hline $\mathrm{T} 1(\mathrm{n}=43)$ & $24(55.8)$ & $13(30.2)$ & $6(14.0)$ & 0.376 \\
\hline $\mathrm{T} 2(\mathrm{n}=12)$ & $10(83.3)$ & 0 & $2(16.7)$ & \\
\hline $\mathrm{T} 3-\mathrm{T} 4(\mathrm{n}=5)$ & $3(60.0)$ & $2(40.0)$ & 0 & \\
\hline
\end{tabular}

carcinoma, one of the tissue samples was moderately stained, whereas the other was negative. The results revealed RCDG1 expression levels in ccRCC tissues were significantly lower than those in non-ccRCC tissues ( $\mathrm{P}=0.005, \chi^{2}$ test, Table II).
Correlation between RCDG1 expression and clinicopathological characteristics in ccRCC and in non-ccRCC samples. It was next investigated whether the expression of RCDG1 correlated to the patients' clinicopathological characteristics 
in ccRCC and non-ccRCC tissues. In ccRCC tissues, as shown in Table IV, RCDG1 expression was negatively correlated with the Fuhrman grade and cases with lower RCDG1 expression showed a significantly higher Fuhrman grade $(\mathrm{P}=0.008$, Kruskal-Wallis test), while no correlation was found with age, gender and tumor state. No significant correlation was observed between RCDG1 expression and any of the characteristics measured in non-ccRCC tissues (Table III).

\section{Discussion}

Although numerous environmental and genetic factors have been associated with RCC, the definitive mechanisms involved in the initiation and progression of RCC have remained elusive $(2,21)$. Recent identification and potential application of molecular tumor markers is expected to reform the clinical staging of RCC and to have an important role in the early diagnosis, individualized treatment and prognostic prediction of RCC patients (22). Until recently, there has been limited use of these molecular markers for RCC (13). Numerous tumor markers have been found to be associated with tumor progression and prognoses of RCC patients. A study by Chuang et al (23) showed that tumor necrosis factor- $\alpha$ (TNF- $\alpha$ ) was able to promote invasion and epithelial-mesenchymal transition of kidney cancer (23). Mutations of the Von Hippel-Lindau (VHL) gene were considered critical for the initiation of ccRCC and loss-of-function mutations have been shown to be correlated with a poor prognosis for patients with ccRCC $(24,25)$. High expression of carbonic anhydrase IX, which is regulated by the Von Hippel-Lindau (VHL) protein (pVHL), was suggested to be correlated with a favorable prognosis and a greater likelihood of response to systemic treatment for metastatic disease $(26,27)$. However, there is still a need to discover renal cancer-associated genes, which promote the mechanisms of pathogenesis, invasion and metastasis of RCC.

A renal cancer-associated gene was newly identified in the present study through bioinformatic, western blot and immunohistochemical analyses. This gene was preliminarily named RCDG1 in this study, however, it is registered as C4orf46 (chromosome 4 open reading frame 46). RCDG1 is located on 4q32.1 with an mRNA of 3,545 bp which encodes a small, conserved and uncharacterized protein C4orf46 (PRO_0000335689). Immunohistochemical staining showed that the protein was predominantly located in the cytoplasm of epithelial cells in the proximal tubules as well as the distal convoluted tubules.

In the present study, western blotting was performed to evaluate the expression of the RCDG1 protein in RCC and normal kidney tissues, RCC cell lines and a normal kidney cell line. The results demonstrated that RCDG1 was significantly downregulated in RCC tissues and renal cancer cell lines, as compared with normal tissues and cell lines. An IHC assay of RCDG1 in paraffin sections of paired RCC and adjacent normal tissues showed comparable results to the western blot analysis. Furthermore, statistical analysis revealed that RCDG1 had a diverse expression pattern across different types of RCC and the downregulation was more marked in ccRCC tissues as compared with other types of RCC (non-ccRCC) tissues. Further analysis showed RCDG1 expression was statistically correlated with the Fuhrman grade in ccRCC cases but not in other types of RCC tissues. This suggested that reduced expression of RCDG1 may be involved in the occurrence and differentiation of ccRCC.

The number of samples used in the present study was moderate but sufficient to reveal the statistically significant differences. The functions of RCDG1 in epithelial cells of renal tubules, involvement in cellular pathways, transcriptional control and mechanisms of downregulation in RCC, however, remain to be elucidated. Recent advances in experimental techniques using knockdown and transgenic overexpression of target genes have facilitated further understanding of the pathogenesis, behavior and molecular biology of cancers $(28,29)$. Functional experiments on renal cancer cell lines through RNA interfere and overexpression of RCDG1 may provide further information for understanding the roles of RCDG1 in RCC. Furthermore, comprehensive analysis of the transcriptional regulation of RCDG1 may help identify the mechanisms of the tumorigenesis and progression of RCC, offering a new target for the emerging targeted therapies.

In conclusion, the present study newly identified a renal cancer-associated gene, preliminarily named RCDG1. RCDG1 was shown to be significantly downregulated in RCC tissues, most markedly in ccRCC tissues. RCDG1 expression was shown to be negatively correlated with the Fuhrman grade in ccRCC, suggesting that the downregulation of RCDG1 may be involved in the tumorigenesis of RCC and the differentiation of ccRCC. Further functional analysis of RCDG1 will offer additional information regarding the role of this gene in RCC.

\section{Acknowledgements}

The present study was supported by the National Natural Science Foundation of China (no. 81101922), Medical Scientific Research Foundation of Guangdong Province of China (nos. A2012584 and A2013606) and Science and Technology Development Fund Project of Shenzhen (no. JCYJ20130402114702124).

\section{References}

1. Jemal A, Siegel R, Xu J and Ward E: Cancer statistics, 2010. CA Cancer J Clin 60: 277-300, 2010.

2. Patel C, Ahmed A and Ellsworth P: Renal cell carcinoma: a reappraisal. Urol Nurs 32: 182-190, 2012.

3. Motzer RJ, Bander NH and Nanus DM: Renal-cell carcinoma. N Engl J Med 335: 865-875, 1996.

4. Cohen HT and McGovern FJ: Renal-cell carcinoma. N Engl J Med 353: 2477-2490, 2005.

5. Jiang Z, Chu PG, Woda BA, et al: Analysis of RNA-binding protein IMP3 to predict metastasis and prognosis of renal-cell carcinoma: a retrospective study. Lancet Oncol 7: 556-564, 2006.

6. Suh JH, Oak T, Ro JY, Truong LD, Ayala AG and Shen SS: Clinicopathologic features of renal cell carcinoma in young adults: a comparison study with renal cell carcinoma in older patients. Int J Clin Exp Pathol 2: 489-493, 2009.

7. Lopez-Beltran A, Scarpelli M, Montironi R and Kirkali Z: 2004 WHO classification of the renal tumors of the adults. Eur Urol 49: 798-805, 2006.

8. Cheville JC, Lohse CM, Zincke H, Weaver AL and Blute ML: Comparisons of outcome and prognostic features among histologic subtypes of renal cell carcinoma. Am J Surg Pathol 27: 612-624, 2003.

9. Choi YD, Kim KS, Ryu S, et al: Claudin-7 is highly expressed in chromophobe renal cell carcinoma and renal oncocytoma. J Korean Med Sci 22: 305-310, 2007. 
10. Fu L, Wang G, Shevchuk MM, Nanus DM and Gudas LJ: Activation of HIF $2 \alpha$ in kidney proximal tubule cells causes abnormal glycogen deposition but not tumorigenesis. Cancer Res 73: 2916-2925, 2013

11. Metcalf JL, Bradshaw PS, Komosa M, Greer SN, Stephen Meyn M and Ohh M: K63-ubiquitylation of VHL by SOCS1 mediates DNA double-strand break repair. Oncogene 20: 1055-1065, 2014.

12. Zhang $\mathrm{N}, \mathrm{Wu} \mathrm{P}, \mathrm{Wu} \mathrm{L}$, et al: The differential expression of vascular endothelial growth inhibitor isoforms, VEGI251, VEGI174 and VEGI192 in human clear-cell renal cell carcinoma. Cancer Genomics Proteomics 10: 47-53, 2013.

13. Wood CG: Molecular markers of prognosis in renal cell carcinoma: Insight into tumor biology helps define risk and provides targets for therapy. J Surg Oncol 94: 264-265, 2006.

14. Fritzsche FR, Riener MO, Dietel M, Moch H, Jung K and Kristiansen G: GOLPH2 expression in renal cell cancer. BMC Urol 8: 15, 2008.

15. Tsimafeyeu I, Demidov L, Stepanova E, Wynn N and Ta H: Overexpression of fibroblast growth factor receptors FGFR1 and FGFR2 in renal cell carcinoma. Scand J Urol Nephrol 45 190-195, 2011.

16. Cairns P: Renal cell carcinoma. Cancer Biomark 9: 461-473, 2010.

17. Lai Y, Yu Z, Wang Y and Ye J: Identification of PCAG1 as a nove prostate cancer-associated gene. Mol Med Rep 7: 755-760, 2013.

18. Krizman DB, Wagner L, Lash A, Strausberg RL and Emmert-Buck MR: The Cancer Genome Anatomy Project: EST sequencing and the genetics of cancer progression. Neoplasia 1: 101 106, 1999.

19. Sun S, Du R, Gao J, et al: Expression and clinical significance of Notch receptors in human renal cell carcinoma. Pathology 41 335-341, 2009.

20. Maaser K, Daubler P, Barthel B, et al: Oesophageal squamous cell neoplasia in head and neck cancer patients: upregulation of COX-2 during carcinogenesis. Br J Cancer 88: 1217-1222, 2003.
21. Janzen NK, Kim HL, Figlin RA and Belldegrun AS: Surveillance after radical or partial nephrectomy for localized renal cell carcinoma and management of recurrent disease. Urol Clin North Am 30: 843-852, 2003

22. Lam JS, Pantuck AJ, Belldegrun AS and Figlin RA: Protein expression profiles in renal cell carcinoma: staging, prognosis, and patient selection for clinical trials. Clin Cancer Res 13: 703s-708s, 2007

23. Chuang MJ, Sun KH, Tang SJ, et al: Tumor-derived tumor necrosis factor-alpha promotes progression and epithelial-mesenchymal transition in renal cell carcinoma cells. Cancer Sci 99: 905-913, 2008

24. Linehan WM, Lerman MI and Zbar B: Identification of the von Hippel-Lindau (VHL) gene. Its role in renal cancer. JAMA 273: 564-570, 1995.

25. Schraml P, Struckmann K, Hatz F, et al: VHL mutations and their correlation with tumour cell proliferation, microvessel density, and patient prognosis in clear cell renal cell carcinoma. J Pathol 196: 186-193, 2002.

26. Bui MH, Seligson D, Han KR, et al: Carbonic anhydrase IX is an independent predictor of survival in advanced renal clear cell carcinoma: implications for prognosis and therapy. Clin Cancer Res 9: 802-811, 2003.

27. Stillebroer AB, Mulders PF, Boerman OC, Oyen WJ and Oosterwijk E: Carbonic anhydrase IX in renal cell carcinoma: implications for prognosis, diagnosis, and therapy. Eur Urol 58: 75-83, 2010.

28. Di Cello F, Shin J, Harbom K and Brayton C: Knockdown of HMGA1 inhibits human breast cancer cell growth and metastasis in immunodeficient mice. Biochem Biophys Res Commun 2013.

29. Loyd CM, Diaconu D, Fu W, et al: Transgenic overexpression of keratinocyte-specific VEGF and Ang1 in combination promotes wound healing under nondiabetic but not diabetic conditions. Int J Clin Exp Pathol 5: 1-11, 2012. 